\title{
Analisis Uji Implementasi Smart Agriculture System Pada Lahan Terbatas Rumah di Wilayah Perkotaan Berbasis Kontrol Menggunakan Mikrokontroler Arduino Uno
}

\author{
Givy Devira Ramady ${ }^{1}$, Andrew Ghea Mahardika ${ }^{2}$ \\ Email : givy.d.ramady@gmail.com, andrewhinata@gmail.com \\ Program Studi Teknik Elektro, Sekolah Tinggi Teknologi Mandala bandung \\ Program Studi Teknik Sipil, Sekolah Tinggi Teknologi Mandala bandung
}

\begin{abstract}
Abstrak
Perkembangan teknologi saat ini, khususnya dibidang otomasi telah mampu meningkatkan nilai efisiensi dan produktifitas. Berdasarkan sebuah kajian riset yang dilakukan oleh lembaga ilmu pengetahuan Indonesia (LIPI) bahwa dalam beberapa dekade kedepan Indonesia memiliki resiko ketahanan pangan yang merupakan dampak dari ketidakseimbangan antara laju pertumbuhan penduduk dengan produksi pangan yang dihasilkan. Salah satu upaya sederhana yang dapat dilakukan untuk mengatasi krisis pangan tersebut berupa pemanfaatan lahan terbatas disekitar pekarangan rumah untuk dijadikan area tanam dengan memanfaatkan teknologi smart agriculture system. Dengan mengintegrasikan smart agriculture system pada media tanam, diharapkan mampu memberikan kemudahan dalam hal perawatan dan pemantauan terhadap kondisi tanaman. Bahan perangkat yang diperlukan dalam membangun smart agriculture system ini berupa modul mikrokontroller Arduino NodeMCU8266, sensor suhu dan kelembaban udara ( sensor DHT-11), sensor kelembaban tanah (sensor soil moisture), mesin pompa air, cloud server thingspeak, dan web application thingspeak. Metode yang digunakan berupa metode penelitian eksperimental dengan pola waterfall, yang mampu menguji hipotesis secara benar dalam hal hubungan kasual melalui tahapan design science research method (DSRM). Berdasarkan hasil pengujian, system dapat bekerja secara baik dan optimal, data hasil pengukuran sensor mampu dikirimkan ke cloud computing thingspeak dan diakses melalui web application performa yang baik dan stabil.
\end{abstract}

Kata kunci : Agriculture, Sensor, Cloud Computing, Application

\section{Pendahuluan}

Perkembangan teknologi saat ini, khususnya dibidang otomasi telah mampu meningkatkan nilai efisiensi dan produktifitas. Berdasarkan sebuah kajian riset yang dilakukan oleh lembaga ilmu pengetahuan Indonesia (LIPI) bahwa dalam beberapa dekade kedepan Indonesia memiliki resiko ketahanan pangan yang merupakan dampak dari ketidakseimbangan antara laju pertumbuhan penduduk dengan produksi pangan yang dihasilkan (1).

Untuk itulah saat ini pemerintah mulai menitik beratkan fokus kajian riset pada pengembangan teknologi pertanian baru dengan mengintegrasikan system kontrol otomasi dengan teknologi informasi dan komunikasi untuk lebih meningkatkan nilai efisiensi dan produktifitasnya (2).

Salah satu upaya sederhana yang dapat dilakukan untuk mengatasi krisis pangan tersebut berupa pemanfaatan lahan terbatas disekitar pekarangan rumah untuk dijadikan area tanam dengan memanfaatkan teknologi smart agriculture system (3-5). Smart agriculture system merupakan sebuah metode pertanian cerdas berbasis teknologi (6), dengan mengintegrasikan smart agriculture system pada media tanam (7), diharapkan mampu memberikan kemudahan dalam hal perawatan dan pemantauan terhadap kondisi tanaman tanpa terkendala oleh jarak dan waktu karena kemampuan sytem yang mampu diakses oleh penggunanya melalui aplikasi secara realtime (8).

Bahan perangkat yang diperlukan dalam membangun smart agriculture system ini berupa modul mikrokontroller Arduino NodeMCU8266, sensor suhu dan kelembaban udara ( sensor DHT-11), sensor kelembaban tanah ( sensor soil moisture), mesin pompa air, cloud server thingspeak, dan web application thingspeak (9). 


\section{A. Arduino NodeMCU8266}

Node MCU adalah sebuah platform IoT yang bersifat open-source. Node MCU berupa sebuah board Arduino ESP-8266 dengan fasilitas Wifi yang sudah terintegrasi. Modul ini digunakan sebagai pengolah nilai data yang diperoleh sensor, yang kemudian akan dikirimkan menuju cloud computing thingspeak melalui saluran komunikasi data internet (10).

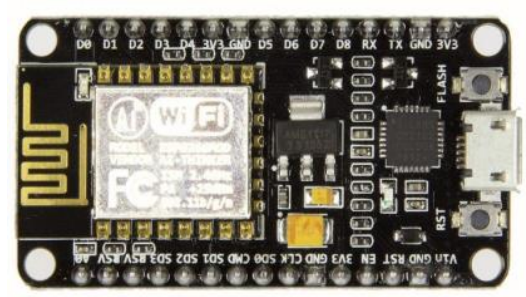

Gambar 1. NodeMCU8266

\section{B. Sensor suhu (DHT-11)}

DHT-11 merupakan sebuah perangkat sensor yang dapat mengukur dua parameter lingkungan sekaligus, yakni suhu dan kelembaban udara. Pada penelitian ini, sensor DHT-11 difungsikan untuk membaca nilai suhu dan kelembaban udara pada objek penelitian yang berupa lingkungan media tanam pada smart agriculture system.

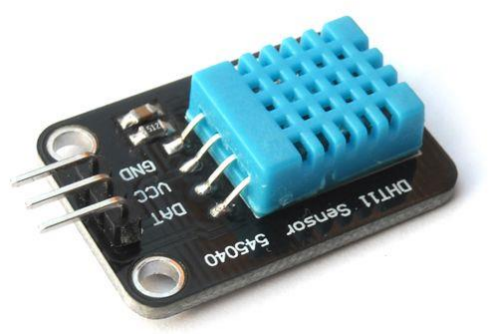

Gambar 2. Sensor DHT-11

\section{Sensor soil moisture YL-69}

Soil moisture merupakan sebuah perangkat sensor kelembaban yang dapat mendeteksi kelembaban dalam tanah. Pada penelitian ini, sensor soil moisture YL-69 difungsikan untuk membaca nilai kelembaban tanah pada objek penelitian yang berupa lingkungan media tanam pada smart agriculture system (11).

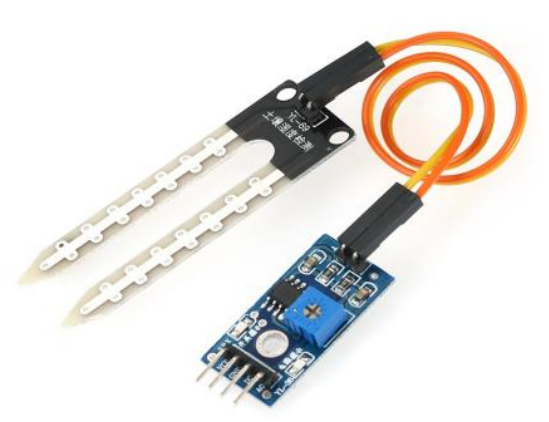

Gambar 3. Sensor soil moisture YL-69

\section{Cloud Server Thingspeak}

Thingspeak merupakan Platform IoT yang dibuat berbasis pada Matlab. Pada platform ini user dapat mengupload data sensor dari berbagai macam development board yang ada. Data yang di upload pada thingspeak bisa dibuat sebagai data pribadi ataupun data public. Data tersebut disajikan dalam bentuk channel yang didalamnya terdapat visualisasi yang diolah oleh matlab.

\section{Metode Penelitian}

Metode yang digunakan pada penelitian ini diantaranya:

1) Metode penelitian eksperimental pola waterfall, dimana metode ini sangat cocok karena sistem yang di bangun akan terus menerus di kembangkan dimana tahapan dari metode ini adalah dimulai dari analisa kebutuhan untuk menunjang penelitian ini, kemudian mendesain sistem, kemudian tahap terakhir adalah implementasi dari sistem/lingkungan yang telah di buat.

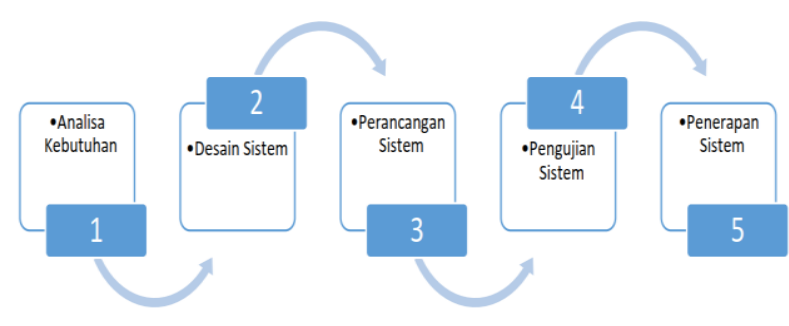

Gambar 4. Metode eksperimental waterfall 
2) Metode deskriptif analitis, yaitu dengan cara menganalisa dan mengidentifikasi permasalahan yang muncul selama penelitian.

3) Studi Kepustakaan, yaitu dengan cara mengumpulkan informasi dari berbagai macam literature yang akan dijadikan sumber serta panduan dalam penyusunan penulisan ini.

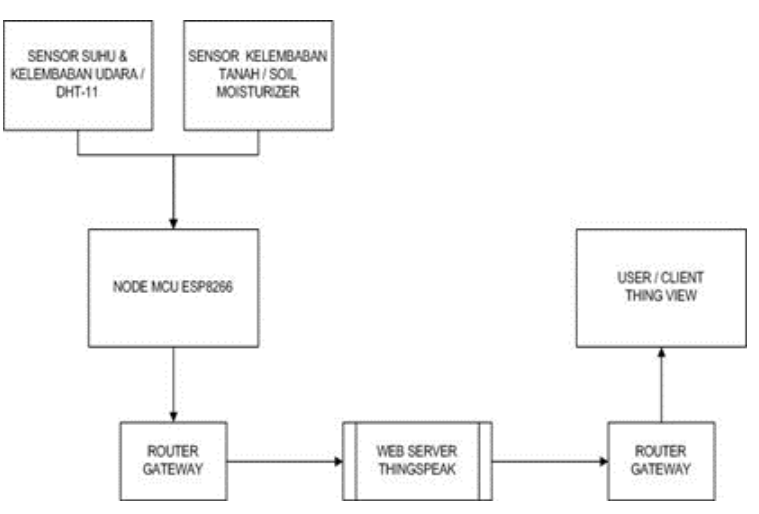

Gambar 5. Desain skema kerja sistem

Tahap awal dimulai dengan proses inisiasi kondisi lingkungan objek penelitian oleh perangkat sensor, nilai yang diperoleh masih berupa data analog yang kemudian akan dikirimkan ke mikrokontroler ESP8266 untuk diproses sehingga data yang diperoleh

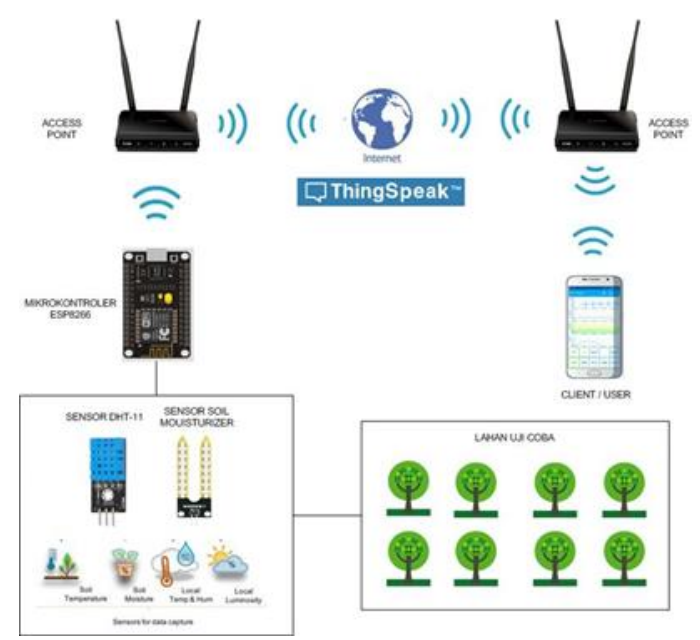

berubah menjadi bentuk digital.

Gambar 6. Desain model sistem
Data tersebut lalau akan ditransmisikan menuju database cloud computing thingspeak melaui jalur komunikasi data internet dan selalu diupdate secara berkala dalam periode waktu tertentu dan dapat diakses secara real time.

Perancangan media tanam dengan mengintegrasikan teknologi smart agriculture system bertujuan untuk meningkatkan nilai efisiensi dan produktifitas. Untuk mencapai target luaran tersebut, ada beberapa tahapan yang harus dikerjakan diantaranya :

\section{A. Desain perancangan perangkat keras}

Tahapan desain perancangan perangkat keras ini dibagi kedalam dua bagian, yaitu :

a) Desain blueprint media tanam
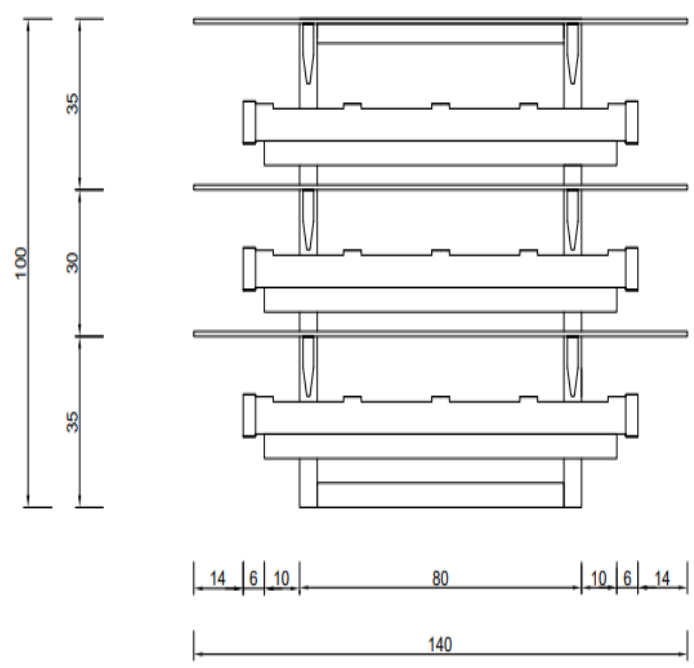

Gambar 7. Desain tampilan depan media tanam
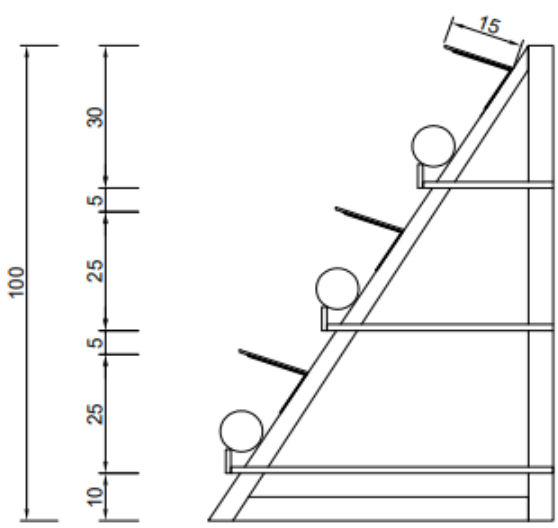
Gambar 8. Desain tampilan samping media tanam

b) Desain unit sistem pengolah data

Smart agriculture system ini tersusun atas beberapa perangkat dan modul seperti mikrokontroler Arduino NodeMCU8266, sensor kelembaban tanah soil moisture, sensor suhu dan kelembaban udara DHT-11, serta jet pump mini.

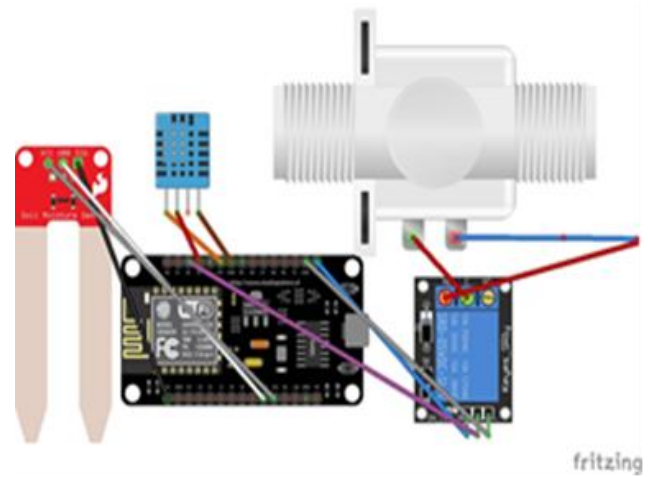

Gambar 9. Desain unit sistem pengolah data

Tabel 1. Hubungan antarmuka perangkat keras

\begin{tabular}{|c|c|c|c|c|}
\hline No & Perangkat & Pin & $\begin{array}{l}\text { Pin } \\
\text { Arduino }\end{array}$ & Keterangan \\
\hline \multirow{3}{*}{1} & \multirow{3}{*}{ Sensor DHT11 } & GND & GND & $\begin{array}{l}\text { Ground untuk } \\
\text { Tegangan }\end{array}$ \\
\hline & & $\mathrm{VCC}$ & $3.3 \mathrm{~V}$ & $\begin{array}{l}\text { Sumber } \\
\text { Tegangan } \\
\text { NodeMCU } \\
\end{array}$ \\
\hline & & DATA & PIN_D3 & $\begin{array}{l}\text { Komunikasi Data } \\
\text { I/O }\end{array}$ \\
\hline \multirow{3}{*}{2} & \multirow{3}{*}{$\begin{array}{l}\text { Sensor Soil } \\
\text { Moisture YL- } \\
69\end{array}$} & GND & GND & $\begin{array}{l}\text { Ground untuk } \\
\text { Tegangan }\end{array}$ \\
\hline & & VCC & $3.3 \mathrm{~V}$ & $\begin{array}{l}\text { Sumber } \\
\text { Tegangan } \\
\text { NodeMCU }\end{array}$ \\
\hline & & DATA & PIN_A0 & $\begin{array}{l}\text { Komunikasi Data } \\
\text { I/O }\end{array}$ \\
\hline \multirow{3}{*}{3} & \multirow{3}{*}{ Relay } & GND & GND & $\begin{array}{l}\text { Ground untuk } \\
\text { Tegangan }\end{array}$ \\
\hline & & VCC & $3.3 \mathrm{~V}$ & $\begin{array}{l}\text { Sumber } \\
\text { Tegangan } \\
\text { NodeMCU } \\
\end{array}$ \\
\hline & & DATA & PIN_D2 & $\begin{array}{l}\text { Komunikasi Data } \\
\text { I/O }\end{array}$ \\
\hline
\end{tabular}

B. Desain perancangan perangkat lunak

Pemrograman dilakukan menggunakan aplikasi perangkat lunak sketch Arduino IDE untuk menyusun list program dan bootloader yang akan diupload kedalam mikrokontroler Arduino NodeMCU8266.

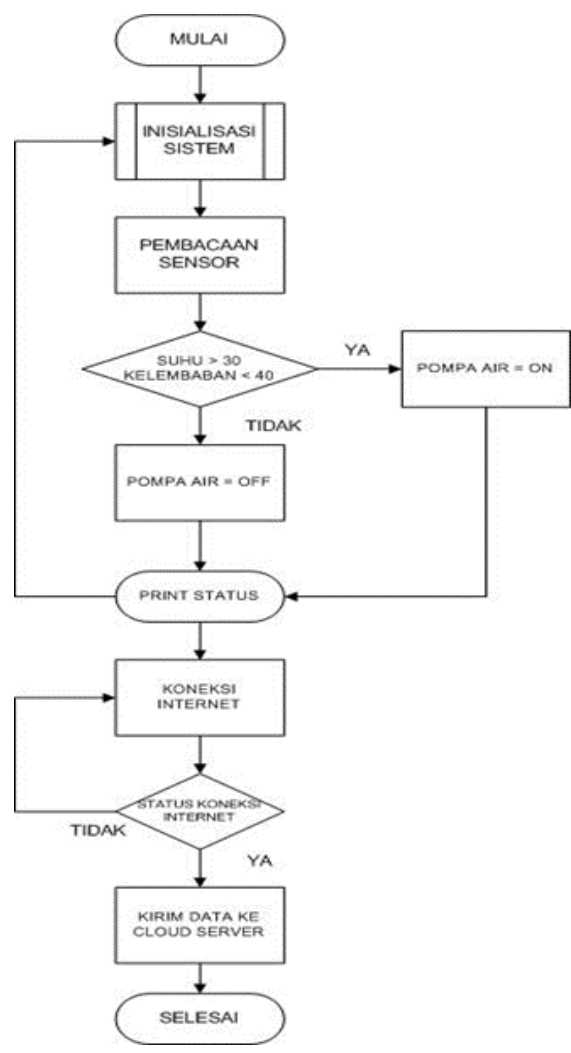

Gambar 10. Flowchart alur program

Besaran parameter nilai yang diinputkan pada program mengacu pada standar parameter yang telah ditetapkan seperti pada table 2 , ini bertujuan agar sistem mampu mendeteksi objek serta memberikan respon akurat mengenai apa yang harus dilakukan ketika memperoleh nilai tertentu dari sensor yang terpasang.

Tabel 2. Parameter suhu dan kelembaban

\begin{tabular}{cccc}
\hline $\begin{array}{c}\text { Suhu } \\
\left({ }^{\circ} \mathrm{C}\right)\end{array}$ & Keterangan & $\begin{array}{c}\text { Kelembaban } \\
\text { Udara }(\%)\end{array}$ & Keterangan \\
\hline$<20^{\circ} \mathrm{C}$ & Kurang Baik & $<40 \%$ & Rendah \\
$\leq 30^{\circ} \mathrm{C}$ & Baik & $\leq 60 \%$ & Normal \\
$>30^{\circ} \mathrm{C}$ & Kurang Baik & $>60 \%$ & Baik \\
\hline
\end{tabular}

\section{Hasil dan Pembahasan}

Tahap akhir dari proses perancangan smart agriculture system ini adalah pengujian kinerja serta performa sistem. Tahapan ini menitik beratkan pengujian terhadap fungsi 
pendeteksian dari sensor yang telah terpasang serta proses pengiriman data ke cloud server thingspeak.

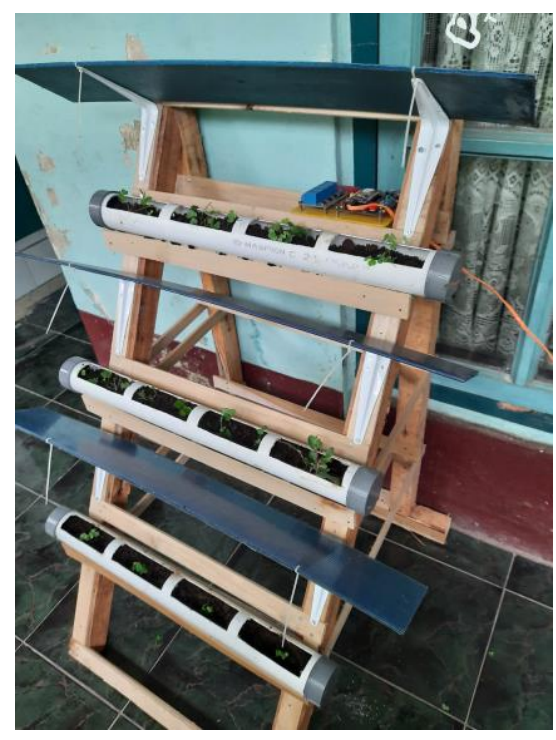

Gambar 11. Perangkat media tanam

Sensor DHT-11 dan sensor soil moisture dipasangkan dan dihubungkan kaki-kaki pin nya pada modul mikrokontroler Arduino NodeMCU8266.

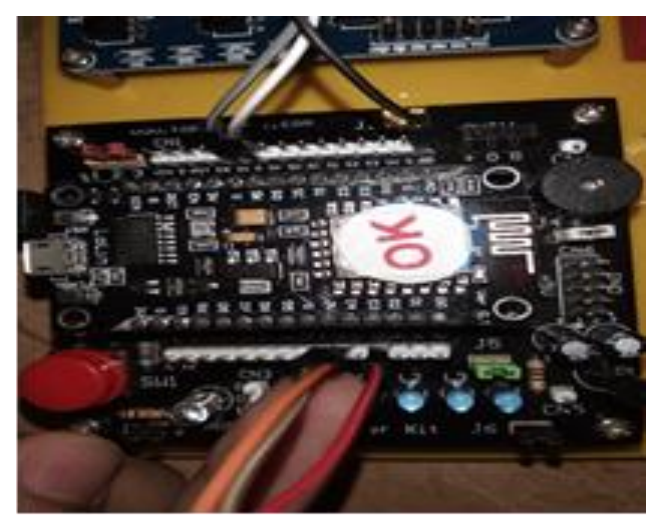

Gambar 12. Pemasangan sensor DHT-11 dan sensor soil moisture YL-69

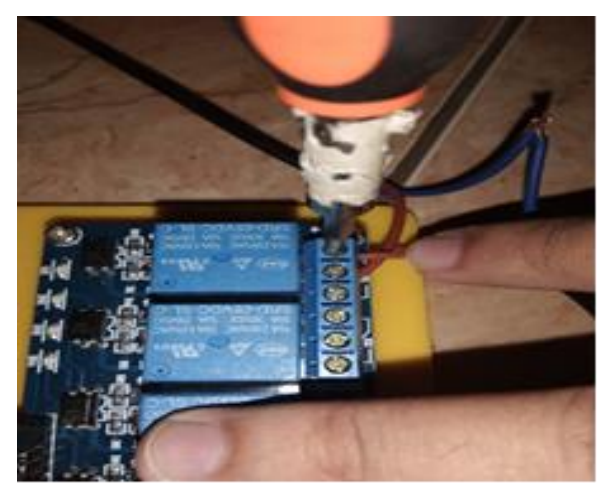

Gambar 13. Koneksi kabel pompa air ke relay
Menghubungkan pompa air dengan relay bertujuan mengotomatiskan saklar ON/OFF, yaitu dengan menghubungkan salah satu kabel dari pompa dengan relay di bagian normal close atau yang berada di tengah relay. Kemudian menghubungkan salah satu kabel dari kabel power dengan relay di bagian normal open atau yang berada di bagian kiri.

\section{1) Pengujian sensor DHT-11}

Proses pengujian Sensor DHT-11 dilakukan dengan cara diletakan pada suatu lokasi tertentu di sekitar lingkungan pengujian.

Tabel 3. Pengujian sensor DHT-11

\begin{tabular}{ccccc}
\hline WAKTU & SUHU & KET & $\begin{array}{c}\text { KELEMBABAN } \\
\text { UDARA }\end{array}$ & KET \\
\hline 07.00 & $26.5^{\circ}$ & BAIK & $81 \%$ & BAIK \\
08.00 & $27^{\circ}$ & BAIK & $78 \%$ & BAIK \\
09.00 & $28^{\circ}$ & BAIK & $77 \%$ & BAIK \\
10.00 & $28^{\circ}$ & BAIK & $72 \%$ & BAIK \\
11.00 & $29.5^{\circ}$ & BAIK & $70 \%$ & BAIK \\
12.00 & $31^{\circ}$ & KURANG & $66 \%$ & BAIK \\
13.00 & $31.5^{\circ}$ & KURANG & $66 \%$ & BAIK \\
14.00 & $31^{\circ}$ & KURANG & $67 \%$ & BAIK \\
15.00 & $30^{\circ}$ & BAIK & $68 \%$ & BAIK \\
16.00 & $29^{\circ}$ & BAIK & $68 \%$ & BAIK \\
17.00 & $28^{\circ}$ & BAIK & $69 \%$ & BAIK \\
18.00 & $28^{\circ}$ & BAIK & $76 \%$ & BAIK \\
19.00 & $26^{\circ}$ & BAIK & $83 \%$ & BAIK \\
\hline
\end{tabular}

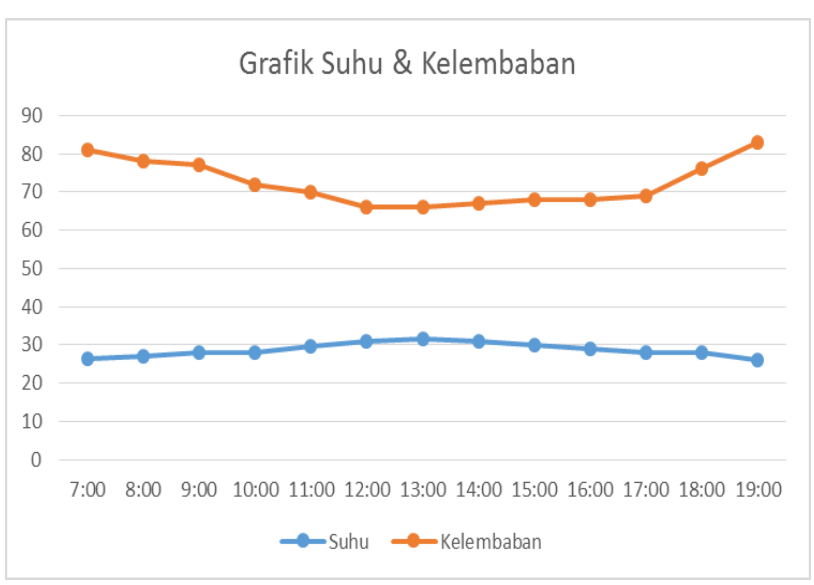


Gambar 14. Grafik pengujian sensor DHT-11

Berdasarkan data hasil pengujian terhadap sensor DHT-11 pada tabel 3, diperoleh nilai suhu dan kelembaban udara yang bervariasi tergantung pada waktu pengujian. Secara umum nilai yang didapat berada pada level kisaran baik yaitu suhu berada direntang <= $30^{\circ}$ dan kelembaban tanah direntang $>60 \%$. Namun pada saat pengambilan sampel uji direntang waktu pukul 12.00 s.d. 14.00 siang nilai status berada pada level kurang baik.

\section{2) Pengujian sensor soil moisture}

Proses pengujian Sensor soil moisture YL-69 dilakukan dengan cara diletakan pada suatu lokasi tertentu di sekitar lingkungan pengujian.

Tabel 4. Pengujian sensor soil moisture

\begin{tabular}{ccc}
\hline WAKTU & $\begin{array}{c}\text { KELEMBABAN } \\
\text { TANAH }\end{array}$ & KET \\
\hline 07.00 & $71 \%$ & BASAH \\
08.00 & $70 \%$ & CUKUP \\
09.00 & $68 \%$ & CUKUP \\
10.00 & $67 \%$ & CUKUP \\
11.00 & $65 \%$ & CUKUP \\
12.00 & $62 \%$ & CUKUP \\
13.00 & $60 \%$ & CUKUP \\
14.00 & $58 \%$ & CUKUP \\
15.00 & $56 \%$ & CUKUP \\
16.00 & $56 \%$ & CUKUP \\
17.00 & $57 \%$ & CUKUP \\
18.00 & $62 \%$ & CUKUP \\
19.00 & $65 \%$ & CUKUP \\
\hline
\end{tabular}

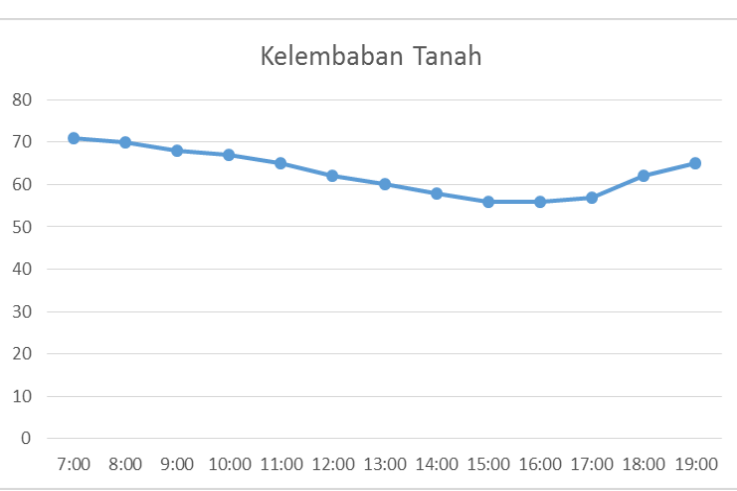

Gambar 15. Grafik pengujian sensor soil moisture

Berdasarkan data hasil pengujian terhadap sensor soil moisture pada tabel 4 , diperoleh nilai kelembaban tanah yang bervariasi tergantung pada waktu pengujian. Secara keseluruhan nilai yang diperoleh berada pada kondisi kisaran cukup yaitu $<=70 \%$. Adapun kondisi pengujian dengan kategori cukup basah diperoleh pada rentang waktu pukul 07.00 .
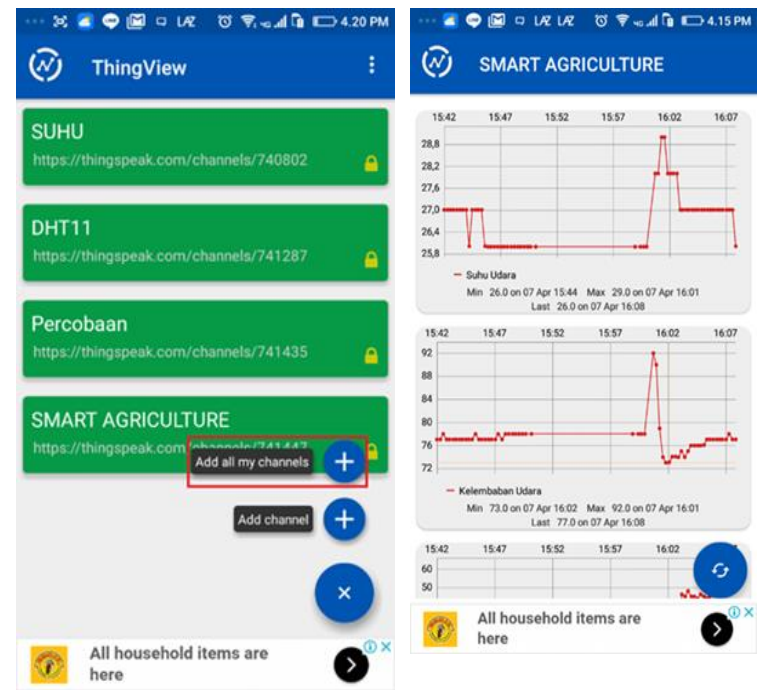

Gambar 16. Tampilan pada aplikasi ThingsView

\section{Kesimpulan}

Sistem dapat berfungsi secara baik dibuktikan dengan data hasil pengujian yang diperoleh. Sensor yang dipasangkan pada sistem mampu bekerja secara optimal dan mampu mengirimkan nilai data hasil pembacaan sensor secara real time ke Cloud Server Thingspeak, sehingga user dapat melakukan pemantauan secara remote melalui aplikasi / web. Untuk memperoleh hasil pengukuran yang lebih akurat dan presisi, direkomendasikan untuk menggunakan sensor soil moisture dengan kualitas yang lebih baik dibandingkan YL-69 yaitu sensor VH4OO. Namun untuk penggunaan umum seperti penerapan smart agriculture system di lingkungan pekarangan tempat tinggal penggunaan sensor soil moisture $Y L-69$ sudah lebih dari mencukupi. Berdasarkan hasil analisa terhadap pengujian system secara keseluruhan, system yang dibuat sudah cukup layak untuk diimplementasikan pada system pertanian cerdas skala kecil/rumahan. 


\section{Daftar Pustaka}

Kelembaban Tanah. 2020;

[1]. Pangan DK. Kebijakan Umum Ketahanan Pangan 2006-2009. J Gizi dan Pangan. 2006;1(1):57-63.

[2]. Ismet $\mathbf{M}$, Indiarto $A D$. Pemanfaatan Teknologi Informasi Dalam Pemasaran Produk Pangan dan Pertanian di Asia. J Pangan. 2006;15(1):15-20.

[3]. Ramady GD, Hidayat R, Syafruddin R, Mahardika AG, Hakim RR. Sistem Monitoring Data pada Smart Agriculture System Menggunakan Wireless Multisensor Berbasis IoT. In: Prosiding Seminar Nasional Teknoka. 2019. p. E518.

[4]. Sulistiyo MW. Smart Agriculture Menggunakan Teknologi Iot (Internet Of Things) Untuk Meningkatkan Produktivitas Pertanian. Program Sistem Informasi S1 Fakultas Teknik Universitas Widyatama; 2019.

[5]. Maulana A. Smart Irrigation System Berbasis Arduino. ELKHA J Tek Elektro. 11(2):115-21.

[6]. Putri AR, Suroso S, Nasron N. Perancangan Alat Penyiram Tanaman Otomatis pada Miniatur Greenhouse Berbasis IOT. Pros SENIATI. 2019;1559.

[7]. Sahara A, Saputra RH, Oktafiani F. Sistem Smart Garden dalam Ruang Berbasis Arduino UNO Microcontroller ATMega 328. PETROGAS J Energy Technol. 2019;1(1):1-12.

[8]. EMILIA NUR FIRDAUS M. Pemanfaatan Iot Pada Automasi Penyiraman Tanaman (Smart Agriculture) Dengan Modul Wi-Fi Esp8266 (Studi Kasus: Tanaman Cabai Pada Lahan Pertanian Pantai Samas). Universitas Pembangunan Nasional Veteran Yogyakarta; 2018.

[9]. Noviardi ST, Dilson S. Internet Of Things (IoT) Refrence Models Dalam membangun Smart Agriculture di indonesia.

[10]. Hidayat L. Rancang Bangun Alat Penyiraman Smart Misting Berbasis Arduino Dengan Metode Vektor Xy. Universitas Stikubank; 2020.

[11]. Widodo AE, Suleman MS. Pemanfaatan Arduino Untuk Mendeteksi 
